\title{
Acute Bacterial Tenonitis and Conjunctivitis following Intravitreal Injection
}

\author{
Lillian Y. Huang Albert O. Edwards \\ Oregon Retina, a Division of Sterling Vision, Eugene, OR, USA
}

\section{Keywords}

Conjunctivitis · Tenonitis · Intravitreal injection $\cdot$ Ocular redness

\begin{abstract}
A 73-year-old man presented 3 days after intravitreal injection (IVI) with bevacizumab for treatment of neovascular age-related macular degeneration with pain and redness around the injection site. Examination showed conjunctival edema and injection around the injection site and a central infiltrate at the injection site consistent with infection of Tenon's capsule and the conjunctiva. Infection of a vitreous wick was considered, but vitreous inflammation was not present. Acute bacterial tenonitis and conjunctivitis were diagnosed, and the patient was prescribed topical antibiotic drops. The patient's symptoms were resolved within $48 \mathrm{~h}$ following the use of topical antibiotic drops, so a culture was not performed. The patient did not develop endophthalmitis. To our knowledge, this is the first reported case of acute bacterial tenonitis and conjunctivitis of the injection site following IVI. Even with the use of betadine, infection of Tenon's capsule and the conjunctiva may occur after IVI and must be differentiated from other causes of postinjection ocular redness such as chemical irritation of the ocular surface, corneal abrasions, and endophthalmitis.
\end{abstract}

\section{Introduction}

Intravitreal injection (IVI) of anti-VEGF agents is commonly performed for the management of retinal disorders, including neovascular age-related macular degeneration, diabetic macular edema, and retinal vein occlusions. Common side effects of IVI include discomfort from mechanical and pharmacological irritation of the ocular surface from lid speculums, the injection itself, and the anesthetic agents and betadine applied to the eye. The most feared complication of IVI is endophthalmitis, which occurs in about 1/5,000 injections [1]. Other adverse effects include subconjunctival hemorrhage, increased intraocular

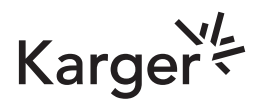


pressure, noninfectious uveitis, vitreous hemorrhage, rhegmatogenous retinal detachment, and choroidal detachment [2]. Here, we report a case of acute bacterial tenonitis and conjunctivitis following IVI which has not been previously observed by us or reported to our knowledge.

\section{Case Report}

A 73-year-old man was evaluated for decreased central vision in his left eye for the past 6 months. His corrected visual acuity was 20/60 in the left eye. Examination was notable for nuclear sclerosis, macular soft drusen, pigment epithelial detachment, subretinal fluid, and slight subretinal hemorrhage. Retinal imaging confirmed the examination findings and he was diagnosed with neovascular age-related macular degeneration. He received an IVI of bevacizumab $1.25 \mathrm{mg}$ after topical anesthesia with proparacaine hydrochloride $0.5 \%$ and application of betadine $10 \%$. The doctor and ophthalmic assistant wore surgical masks during the procedure to minimize risk of infection.

Three days later, the patient reported redness and a dull ache in the temporal quadrant of his left eye. Slit-lamp examination showed a white infiltrate at the injection site and conjunctival injection at and around the injection site in the left eye (shown in Fig. 1). A diagnosis of presumed acute bacterial tenonitis and conjunctivitis was made. There was concern that the patient might develop endophthalmitis, but no inflammation was seen in the vitreous. Scleral depression was not performed due to discomfort, and the patient was instructed to instill 1 drop of ciprofloxacin $0.3 \%$ into the left eye every $2 \mathrm{~h}$ for the next 2 days.

Two days later, he presented with foreign body sensation and lessened pain. The examination showed that the white infiltrates and conjunctival injection were decreased. There was no vitreous inflammation. Because the patient's symptoms were greatly improved within $48 \mathrm{~h}$ by use of antibiotic drops, a culture was not performed. The patient was instructed to decrease the frequency of use of ciprofloxacin $0.3 \%$ to 6 times per day in the affected eye and return for follow-up in 1 week. The patient returned for follow-up 7 days after the injection with resolution of the foreign body sensation in his left eye. Slit-lamp examination revealed normal findings, and the patient was instructed to discontinue the use of ciprofloxacin $0.3 \%$.

\section{Discussion/Conclusion}

Ocular redness and discomfort are common after IVI and typically subside within a few hours or less. The ocular redness induced by chemical conjunctivitis [3], subconjunctival hemorrhage, corneal abrasions, keratopathy, dry eye, and blepharitis must be distinguished

Fig. 1. Postinjection tenonitis and conjunctivitis. Purulent infiltration of the injection site with surrounding conjunctival injection 3 days following IVI with bevacizumab. IVI, intravitreal injection.

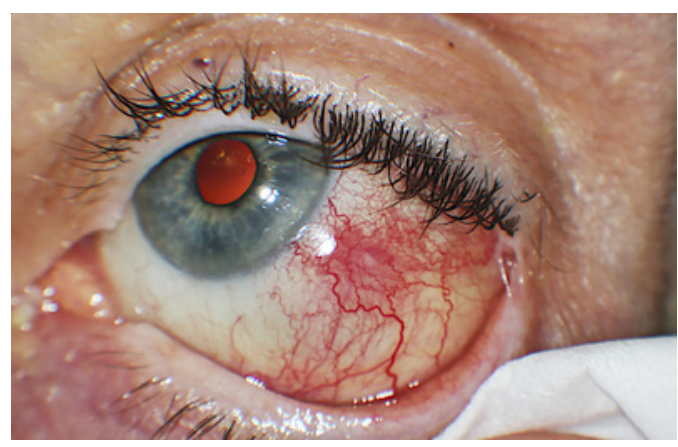


from more serious adverse events such as endophthalmitis. We now add bacterial infection of the injection site to the differential of postinjection conjunctival redness.

Although bacterial conjunctivitis is a common ophthalmic condition that often resolves spontaneously without the help of topical antibiotics [4], we believe injection site infections should be aggressively treated and followed due to the risk of tenonitis, infectious scleritis [5], and endophthalmitis if a vitreous wick was present [6]. Conjunctivitis-causing bacteria can infect the conjunctiva via fingers carrying the bacteria, the eyelids, eyelashes, and skin surrounding the eye, the nasopharynx, or contaminated eye drops and contact lenses [7]. The patient reported that he consistently uses artificial tears in both eyes twice daily, which increased his risk of developing conjunctivitis due to contaminated eye drops.

Gines et al. [8] have also shown that even with the use of betadine $10 \%$ at the injection site prior to IVI, bacteria can persist on the ocular surface. In accordance with the finding made by Wen et al. [9] that wearing a face mask can minimize the risk of bacterial contamination during IVI, the doctor and assistant both wore surgical masks. The patient was instructed not to speak during the procedure but did not wear a surgical mask.

The white infiltrate at the injection site with surrounding conjunctival inflammation and delayed onset of pain were suggestive of bacterial infection in this patient. Because $S$. Epidermidis is a leading cause of endophthalmitis $[4,10]$, we considered that as a likely etiology and prescribed topical ciprofloxacin $0.3 \%$ every $2 \mathrm{~h}$. There was concern the patient might develop endophthalmitis through the vitreous wick that can occur after IVI or infectious tenonitis or scleritis, but the patient improved quickly. This case illustrates the importance of examination of delayed ocular redness and pain after IVI to ensure accurate diagnosis and appropriate management.

\section{Statement of Ethics}

The patient consented in writing to the publication of the case and associated images.

\section{Conflict of Interest Statement}

The authors have no conflicts of interest to share.

\section{Funding Sources}

No funding or grant support.

\section{Author Contributions}

Lillian Y. Huang drafted the case report and formatted the manuscript for submission. Albert 0. Edwards revised the case report and gave final approval for the version to be submitted.

\section{Karger'}


Huang and Edwards: Acute Bacterial Tenonitis and Conjunctivitis following Intravitreal Injection

\section{References}

1 Daien V, Nguyen V, Essex RW, Morlet N, Barthelmes D, Gillies MC, et al. Incidence and outcomes of infectious and noninfectious endophthalmitis after intravitreal injections for age-related macular degeneration. Ophthalmology. 2018 Jan 1;125(1):66-74.

2 Falavarjani KG, Nguyen QD. Adverse events and complications associated with intravitreal injection of antiVEGF agents: a review of literature. Eye. 2013;27:787-94.

3 Ha D, Choi S-R, Kwon Y, Park H-H, Shin J-Y. Pattern of adverse events induced by aflibercept and ranibizumab A nationwide spontaneous adverse event reporting database. 2007-2016. Medicine. 2019 [cited 2020 May 10];98(33):e16785.

4 Epling J. Bacterial conjunctivitis. BMJ Clin Evid. 2012;2012:0704.

5 Coussa RG, Wakil SM, Saheb H, Lederer DE, Oliver KM, Cheema DP. Anterior infectious necrotizing scleritis secondary to Pseudomonas aeruginosa infection following intravitreal ranibizumab injection. Am J Ophthalmol Case Rep. 2017 Apr 1;5:16-9.

6 Chen SDM, Mohammed Q, Bowling B, Patel CK, Moshfeghi DM, Kaiser PK, et al. Vitreous wick syndrome: a potential cause of endophthalmitis after intravitreal injection of triamcinolone through the pars plana. Am J Ophthalmol. 2004;137:1159-60.

7 Høvding G. Acute bacterial conjunctivitis. Acta Ophthalmol. 2008 Jun 28;86(1):5. Available from: http://doi. wiley.com/10.1111/j.1600-0420.2007.01006.

8 Gines JC, Nentwich MM, Peggy Bedoya AH, Cibils P, Esteche A, Laspina F, et al. Bakterielle Kontamination von Injektionskanülen nach intravitrealer operativer Medikamenteneingabe in Paraguay. Ophthalmologe. 2012 Aug;109(8):782-7.

9 Wen JC, McCannel CA, Mochon AB, Garner OB. Bacterial dispersal associated with speech in the setting of intravitreous injections. Arch Ophthalmol. 2011 Dec 1;129(12):1551-4.

10 Tarragó R, Olea JL, Ramírez C, Escudero L. Endophthalmitis after intravitreal injections. Incidence, management and prognosis. Arch Soc Esp Oftalmol. 2017 Mar 1;92(3):107-11. 